\title{
THE BEHAVIOUR OF EXTERIOR BEAM-COLUMN JOINTS
}

\author{
T. Paulay* and A. Scarpas**
}

\section{ABSTRACT}

Analytical models for the design of column-beam joints in earthquake resisting multistorey frames, largely developed in New Zealand, are reviewed. These models were based on evidence obtained from the study of interior joints. To verify the applicability of such models also to exterior beam-column joints, where a better anchorage for the beam reinforcement is possible, three units were tested under reversed cyclic simulated seismic loading. Excellent response was exhibited in spite of the use in two units of only about one half of the currently recommended amount of horizontal joint shear reinforcement. After a detailed description of the observed performance of each test unit, an explanation is offered for the surprisingly good response.

\section{INTRODUCTION}

Some fifteen years ago a systematic study of the behaviour and strength of beamcolumn joints of earthquake resisting reinforced concrete frames was begunl, 2, 3. These studies were stimulated by the realization that under typical seismic loading, shear forces introduced to joints of frames are usually very much larger than those occurring. under gravity loading. Moreover, the formation of plastic hinges in beams or columns adjacent to a joint and the reversed cyclic nature of the loading suggested that, in addition to the problems of shear resistance, serious difficulties with the anchorage of yielding bars may also arise.

In a number of projects contributions to these issues were also made in New Zealand $4,5,6,7,8,20$. Most of these tests showed that horizontal joint shear reinforcement, suggested in the early $70^{\prime} \mathrm{s}^{9}$, was inadequate to ensure the satisfactory hysteretic response of such column-beam assemblies. Shear failures of joints by both diagonal tension and compression, were frequently encountered. Also in several cases significant pullout of beam bars from the joint, or slip of continuous column bars at the outer face of exterior joints, were observed10. In these early tests at the University of Canterbury, the main bars were placed only at the outer and inner faces of the columns i.e. no intermediate column bars subjected to low flexural strains and commonly used in multistorey construction were provided.

It was also realised that the loading conditions, in terms of shear and anchorage of bars, are even more severe for interior

* Professor of Civil Engineering

* * Research Assistant, Department of Civil Engineering, University of Canterbury, Christchurch, New Zealand. beam-joints. In these both, the beam and column bars usually pass continuously. through the joints.

A study of interior joints lead to the postulation of a simple structural model 10,11 which could be used by designers to proportion and reinforce interior beam column joints. A significant feature of this model was the realization that joint shear reinforcement is necessary in both the horizontal and the vertical directionslo. This lead subsequently to the recommendation that in addition to horizontal stirrup ties, intermediate column bars should pass through the joint, providing the necessary vertical joint shear reinforcement 12 .

In a series of carefully planned and generously instrumented tests with interior beam-column assemblages 13,14 , it was demonstrated that excellent hysteretic response could be attained when joints were proportioned in accordance with the proposed analytical modello. In all cases the extensive yielding, and hence energy dissipation, could be confined to the plastic hinges in adjacent beams, as intended.

The importance of vertical joint shear reinforcement, in the form of intermediate column bars passing through the joint, was convincingly demonstrated by Park and Keong15,16. In one series of tests, columns with flexural reinforcement placed in the two opposite faces of the column only, close to the fibres of maximum flexural strain, were used. In spite of the use of large quantities of horizontal joint shear reinforcement, joint shear failures occurred 15 . In a subsequent study 16 beams and columns, identical to those of the previous project, were used, except that intermediate columns bars, providing vertical joint shear reinforcement, were also provided. A dramatic improvement in hysteretic response without joint failure was observed16.

The extensive study of interior beamcolumn joints, only highlights of which were outlined above, and the deliberations within the New Zealand National Society for Earthquake Engineeringl2, were used to formulate recommendations for the design of both types of beam-column joints in the Draft New Zealand Standard Code of Practice for the Design of Concrete Structuresl7. No particular distinctions in the design of exterior or interior joints were madel2,17.

It was realised that, because of the more effective anchorage of beam bars by means of $90^{\circ}$ hooks or special anchorage plates, the loading conditions at exterior joints are more favourable than those identified for interior beam-column joints. However, in the absence of experimental evidence, that should have been obtained from 
specimens constructed in accordance with these new proposals12, no concession for design of exterior joints could be offered17. Details of the improved conditions for exterior joints are discussed subsequently.

The purpose of the project reported here was to:

Test exterior beam-column joints which were designed and detailed in accordance with the principles recently developed in New Zealand12,17, and to study their behaviour.

(ii) To identify differences in the response of exterior and interior joints of similar proportions, when subjected to similar loading or displacement sequences.

(iii) To make recommendations, if necessary, for the modification of existing design procedures relevant to exterior beam-column joints.

The significant difference between the specimens used in this projectl 8 and those studied several years ago $4,5,6,7,8$, was that intermediate column bars, providing joint shear resistance in the vertical direction, were used in the units described subsequently. It is believed that this feature of detailing was responsible for the dramatic improvement of behaviour in comparison with those observed in earlier tests.

\section{ASSUMED JOINT BEHAVIOUR}

\subsection{A Joint Model}

The internal actions assumed to be generated at the core of an exterior beamcolumn joint, when due to earthquake loading a plastic hinge developes in the beam, are shown in Fig. l(a). The tensile and compression steel forces, introduced by the beam and column reinforcement to the concrete of the joint core, are labelled as $T, T^{\prime}, T^{\prime \prime}$ and $C_{S}, C_{S}^{\prime}, C_{S}^{\prime \prime}$ respectively. The compression forces, i.e. resultants of the concrete compression stresses, applied by the three adjacent members to the joint core, are in turn shown as $\mathrm{C}_{C}, \mathrm{C}_{\mathrm{C}}^{\prime}$ and $\mathrm{C}_{C}^{\prime \prime}$. At the boundaries of the joint core, shear forces from the beam, $v_{b}$, and the columns, $v_{c o l}$ and $V_{\text {Coll, }}^{\prime}$ are also introduced.

The total horizontal joint shear force

$$
\mathrm{V}_{j h}=\mathrm{T}-\mathrm{V}_{\mathrm{col}}
$$

and a similar vertical joint shear force, generally lead to excessive diagonal tensile stresses in the concrete core so that diagonal tension cracks, such as shown in Fig. I (b), develop. A model is thus necessary which can satisfactorily simulate the disposition and transfer of internal forces after the development of diagonal cracks in the joint.

\subsection{Mechanisms of Joint Shear Resistance}

The diagonally cracked concrete in the joint core can efficiently transfer diagonal compression forces, approximately parallel to the cracks. Forces from the beam and column reinforcement are transferred to the concrete by means of bond stresses or by bearing within the bend, where this is provided. These actions are qualitatively shown in Fig. $1(b)$.

During the first inelastic loading of the beam, for which a typical crack pattern is shown in Fig. I(b), the greater part of the flexural compression force in the beam is transferred to the joint core by concrete compression stresses. (Fig. I(a)). The remainder of the compression force is introduced to the core by the compression (bottom) bars in the beam, where excellent conditions for bond transfer prevail. For the purpose of this study it is assumed that yielding in the column reinforcement does not occur at any stage of the loading.

The tension force from the beam in Fig. 1 (b) is transferred to the core concrete by bond stresses and by bearing stresses within the bend of the anchorage of top bars. As yield strains along the tension (top) reinforcement spread also into the joint area, bond along the straight portion of the beam bars will gradually diminish. Therefore the larger part of the total tension force $T$ may need to be transferred to the concrete core within the bend of these bars.

It is evident that these forces, transferred to the concrete core at diagonally opposite corners of the joint, can be resisted by a strong and relatively rigid concrete strut.

Fig. 2 (a) shows for example that at the lower right hand corner of the joint, the horizontal concrete force $C_{C}$, together with the major part of the horizontal steel compression force $\mathrm{C}_{S}$, and the column shear force $V_{C}^{\prime}$ l can combine with similar vertical forces, $C_{C}^{\|}, \Delta T "$ and $V_{b}$, to introduce the diagonal strut force $\mathrm{D}_{\mathrm{C}}$. This system to be in equilibrium, does not require any contribution from horizontal or vertical joint shear reinforcement.

The remainder of forces, introduced by beam and column bars to the joint core by means of bond, and not transferred by the strut mechanism shown in Fig. 2(a), may be assumed to be resisted by a truss mechanism. As shown in Fig. 2(b), the shear force introduced at a node point at the face of the joint can be resolved into a diagonal compressive component $D_{S i}$ acting along the $i-t h$ strut and a vertical or horizontal tension component $\mathrm{T}_{i}$ which needs to be carried by steel reinforcement. Because of the relatively long tension path of the internal forces, usually involving large steel strains, this system is much more flexible than the one shown in Fig. 2(a).

It is emphasized that at the first loading of the beam, the majority of the joint shear forces will be resisted by the strut mechanism shown in Fig. 2(a). This is because large forces are introduced by the concrete in flexural compression and 
FIGURE 1 - FORCES ACTING ON A JOINT CORE

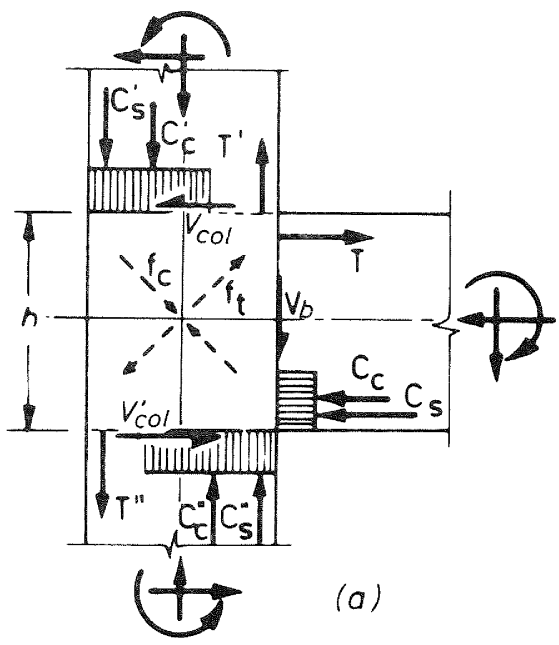

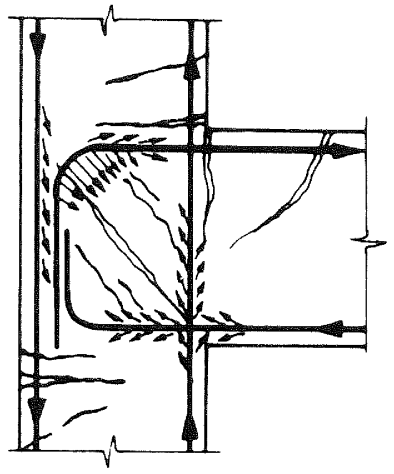

(b)

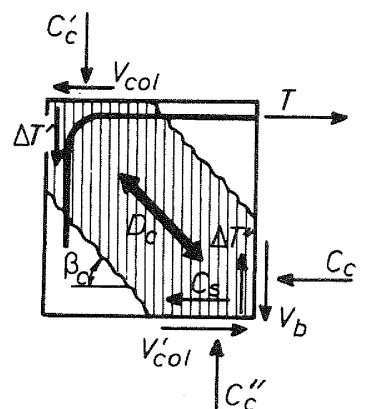

(a) Concrete Strut Mechanism

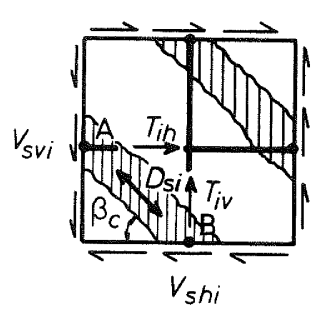

(b) Truss Mechanism

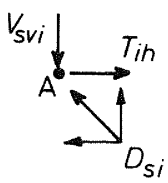

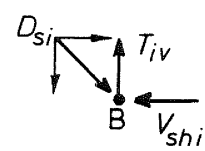

FIGURE 2 - MECHANISMS OF JOINT SHEAR RESISTANCE

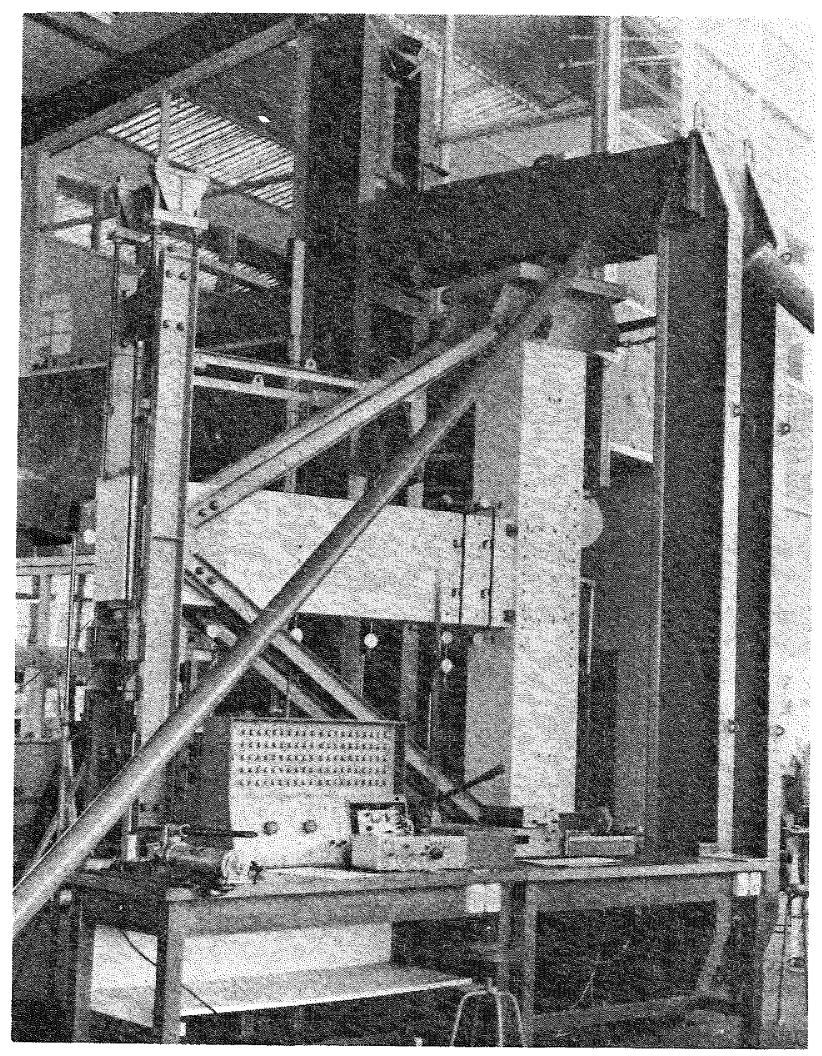


because of good bond conditions around the beam bars. The insignificant contribution of the truss mechanism (Fig. 2(b)) at this stage of the loading has been verified experimentally in both interior 14,19 and exteriorl8 joints.

\subsection{Effects of Inelastic Reversed Cyclic Loading}

Because of residual inelastic strains in the beam bars, large flexural cracks previously formed at or near the column face, will not close completely upon stress reversal. Therefore most, if not all, the internal beam forces will be transferred to the joint core by the beam bars only. For the compression bars this necessitates the generation of significant bond forces.

As a result of the drastic reduction, or more commonly complete elimination, of the concrete compression force in the beam, shown as $C_{C}$ in Fig. $1(a)$ and Fig. 2(a), the horizontal component of the previous significant strut force, $D_{C}$, cannot be sustained. Consequently the major part of the horizontal joint shear force would need to be transferred by the truss mechanism, shown in Fig. 2 (b).

This redistribution of the shear resistance from the strut to the truss mechanism in interior beam-column joints, examined in detail elsewherell, was repeatedly observed in experiments 13,14,19. After a number of reversed load cycles, to a displacement ductility of 4 to 6 , the contribution of the strut mechanism to shear resistance was found to be very small unless the column was subjected also to significant axial compression. For this reason it was recommended that in beam column joints, where beam hinges can develop adjacent to the joint and when the average compressive stress on the column is less than $0.1 \mathrm{f}_{\mathrm{C}}^{\prime}$ ' the entire shear resistance be allocated to the truss mechanism, requiring both horizontal and vertical joint shear reinforcement12,17,19. Interior beam column joints so designed were found to perform satisfactorilyl4. When joint shear reinforcement was provided for only a fraction of the total joint shear force, joint shear failure terminated the capacity of beamcolumn assemblages after a limited number of excursions into the inelastic range of response16,19.

When these design recommendations 12,17 were made, no experimental evidence was available to verify the validity of the approach also with respect to exterior beamcolumn joints. It was thought, however, that the procedure, when applied to exterior joints, was conservative rather than unsafe.

\section{THE TEST PROGRAM}

\subsection{Details of Test Specimens}

To allow the reuse of existing testing facilities and to enable a more meaningful comparison to be made with interior beamcolumn joint tests, specimens of the type shown in Fig. 3 were chosen. General details and the overall dimensions of all three units, as shown in Fig. 4, were identical. However, the horizontal joint shear reinforcement was varied and in Unit 2 additional beam reinforcement was used to increase its flexural strength. Thereby larger shear load was imposed on this joint. Beam and column sizes and lengths were identical to those used for interior beam-column assemblages of two previous projects 14,19 .

The yield strengths of the RIO and Rl2 plain bars used for stirrups and ties, and the D20 and D24 deformed bars used for the principal reinforcement in the beams and columns were $316,326,296$ and $300 \mathrm{MPa}$ respectively. The compressive strengths of the concrete at the time of the testing of Units 1,2 and 3 'were $22.6,22.5$ and $26.9 \mathrm{MPa}$ respectively. The reinforcement was preassembled and placed in a formwork. concreting was carried out in a single operation while the specimens were flat on the floor of the laboratory. After 7 days of standard curing, the units were kept in the laboratory till testing at the age of 38 to 61 days. Sufficient instrumentation was provided to monitor deflections, shear distortions in the joints and steel strains in some of the beam and column barsas well as in several joint stirrup-ties. Full details are given elsewherel8.

As seen in Fig. 3 the units were tested in a vertical position. The column ends were held in position horizontally, while they were subjected to predetermined concentric axial compression force. The beam, acting as a cantilever, was subjected to reversed cyclic point load at its free end. The typical loading program is shown in Fig. 5. The first two load controlled elastic cycles to $75 \%$ of the theoretical yield strength of the beam were followed by pairs of displacement controlled loading cycles corresponding with progressively increased displacement ductility demands.

\subsection{Design Strengths of Specimens}

As the aim of the test was to study the behaviour and strength of the joint in relation to the plastic hinge development in the beam, the ideal flexural strength of the column was made larger than

that required to resist the beam load input at ideal strength, and based on measured properties. This would correspond with the strength hierarchy achieved in multistorey frames, designed in accordance with the suggestions of the recent draft New zealand code for concrete structures 17 .

Adequate shear reinforcement in all members precluded shear failures. Beam bars were anchored by a $90^{\circ}$ hook at the far face of the column. The straight portion of the beam bars past the $90^{\circ}$ bend, corresponded approximately with the length derived from current code specifications 17 . Anchorage distress was not detected in any of these tests.

The significant strength properties and various ratios of joint shear strengths are assembled for all units in Table $I$.

UNIT 1 was intended to meet the requirements of the current New Zealand draft 


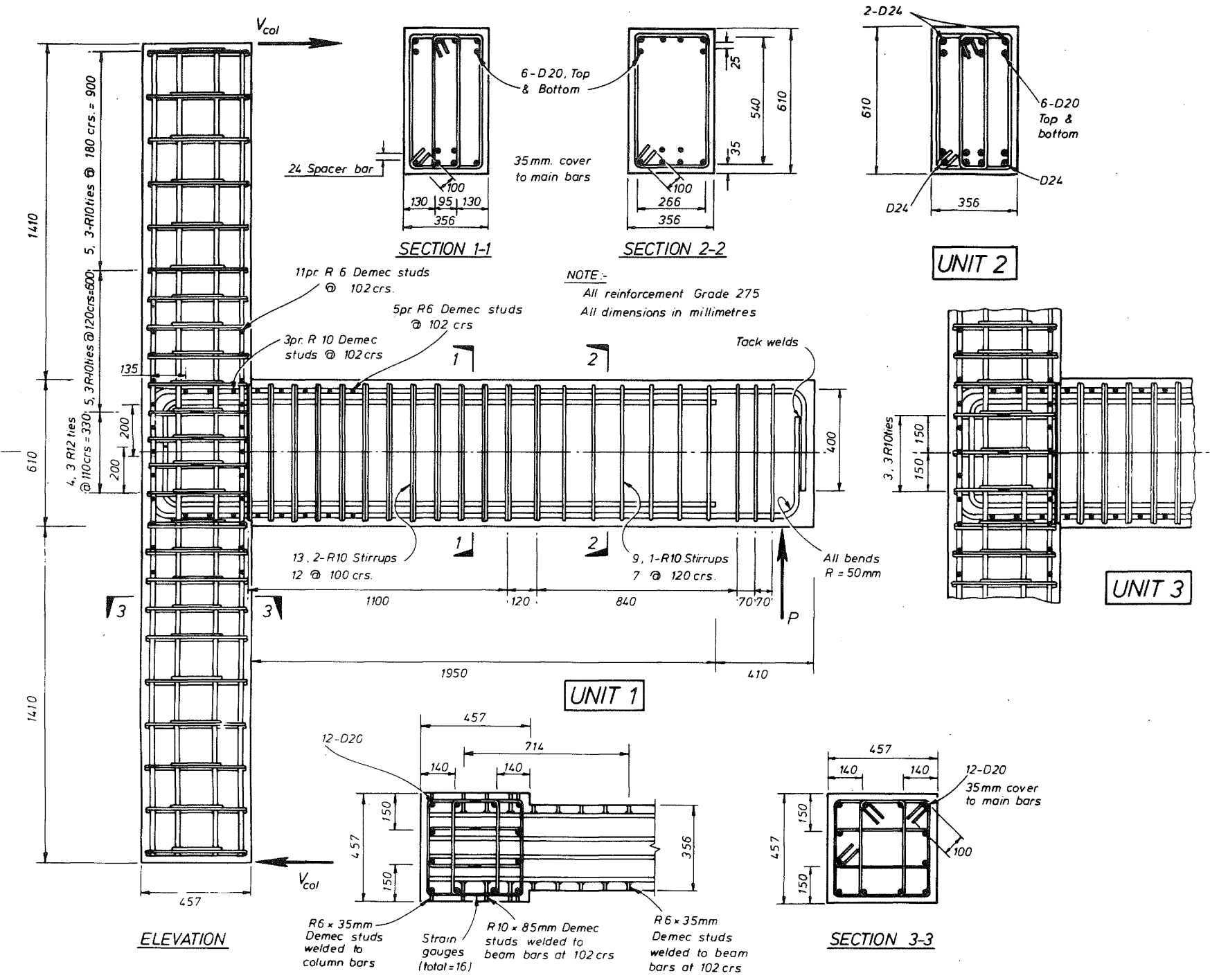

FIGURE 4 - DETAILS OF TEST SPECIMENS

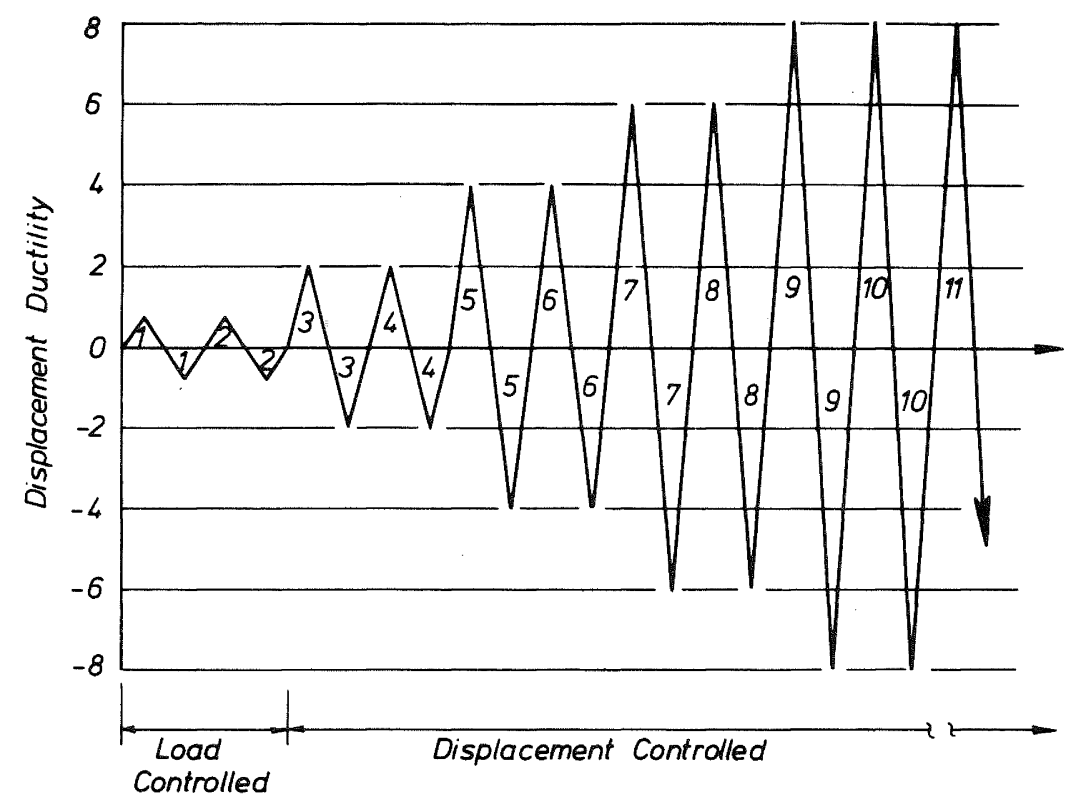


TABLE I - STRENGTH PROPERTIES OF UNITS

\begin{tabular}{|c|c|c|c|c|}
\hline No & Property & Unit I & Unit 2 & Unit 3 \\
\hline 1 & $A_{S}(\mathrm{~mm})$ & 1885 & 2790 & 1885 \\
\hline 2 & $\left(d-d^{\prime}\right)(m m)$ & 490 & 474 & 490 \\
\hline 3 & $\mathrm{M}_{i}(\mathrm{kNm})$ & 254 & 364 & 254 \\
\hline 4 & $\mathrm{M}_{\mathrm{ix}}(\mathrm{kNm})$ & 273 & 393 & 273 \\
\hline 5 & $N /{ } \operatorname{cx}^{A} g$ & 0.053 & 0.150 & 0.053 \\
\hline 6 & $v_{j h}(k N)$ & 546 & 813 & 546 \\
\hline 7 & $v_{j h} / \sqrt{f_{c}^{\prime}}$ & 0.49 & 0.74 & 0.49 \\
\hline 8 & $\mathrm{~V}_{\mathrm{ch}}(\mathrm{kN})$ & - & 165 & - \\
\hline 9 & $\mathrm{~V}_{\mathrm{sh}}(\mathrm{kN})$ & 546 & 648 & 546 \\
\hline 10 & $v_{j h x}(k N)$ & 470 & 702 & 470 \\
\hline 11 & $\mathrm{~V}_{\operatorname{shx}}(\mathrm{kN})$ & 589 & 397 & 298 \\
\hline 12 & $v_{s h x} / v_{j h}$ & 1.079 & 0.488 & 0.546 \\
\hline 13 & $v_{\operatorname{sh} x} / v_{j h x}$ & 1.253 & 0.566 & 0.634 \\
\hline 14 & $\mathrm{v}_{\text {sh }} / \mathrm{v}_{\text {sh }}$ & 1.079 & 0.613 & 0.546 \\
\hline 15 & $\mathrm{v}_{\mathrm{jv}}(\mathrm{kN})$ & 728 & 1085 & 728 \\
\hline 16 & $\mathrm{~V}_{\mathrm{cV}}(\mathrm{kN})$ & 475 & 814 & 475 \\
\hline 17 & $\mathrm{~V}_{\mathrm{sv}}(\mathrm{kN})$ & 253 & 271 & 253 \\
\hline 18 & $\mathrm{~V}_{\mathrm{svx}}(\mathrm{kN})$ & 372 & 372 & 372 \\
\hline 19 & $\mathrm{~V}_{\text {shx }} / \mathrm{V}_{j, \text { test }}$ & 0.781 & 0.401 & 0.396 \\
\hline
\end{tabular}

Notes:

1. Area of top or bottom reinforcement at the critical beam section.

2. Effective internal lever arm of beam.

3. Ideal flexural strength of beam based on $\mathrm{f}_{\mathrm{y}}=275 \mathrm{MPa}$.

4. Ideal flexural strength of beam based on measured yield strength of steel. The subscript $x$ in all subsequent symbols refers to the appropriate strength corresponding with the measured yield strength.

5. Axial load intensity index.

6. Total horizontal design joint shear force corresponding with the flexural overstrength of the beam.

7. Ratio of horizontal joint shear to $\sqrt{f^{\top}}$, indicating that this is well within the suggested 17 maximum of 1.5 .

8. Design horizontal joint shear force assigned to the concretel.

9. Design horizontal shear force assigned to the joint shear reinforcement, derived as $v_{s h}=v_{j h}-v_{c h}$.
10. Total horizontal joint shear force developed with the ideal flexural strength of the beam based on measured properties.

11. Horizontal joint shear resistance of the stirrup-ties, as provided with measured yield strengths.

15. Estimated ${ }^{17}$ total vertical design joint shear force.

16. Design vertical joint shear force assigned 17 to the concrete.

17. Design vertical joint shear force assignedl7 to the joint shear reinforcement computed from $v_{S V}=v_{j v}-v_{C V}$.

18. Shear resistance of total vertical joint shear reinforcement, consisting of 4 intermediate column bars, based on measured yield strength. This is seen to be some $40 \%$ in excess of that required.

19. Ratio of ideal shear strength of horizontal joint shear reinforcement to maximum total joint shear force $v_{j}$, test encountered during the test.

codel 17 recommendations. Because the column was subjected to only small axial compression $\mathrm{N}$, joint shear reinforcement was to be provided for the entire joint shear force at the development of the theoretical flexural overstrength of the beam. As item 12 of Table I shows $107.8 \%$ of the design joint shear force was provided for on the basis of measured yield strengths of the reinforcement.

UNIT 2 was intended to be tested with a significant axial load on the column i.e. $\mathrm{N}=0.44 \mathrm{f}_{\mathrm{C}}^{\prime} \mathrm{A}_{\mathrm{g}}$. Correspondingly some of the joint shear resistance was to be assigned to the strut mechanism i.e.

$$
v_{c h}=\frac{2}{3} \sqrt{\frac{N}{A_{g}}-\frac{f_{C}^{T}}{I 0}}\left(b_{j} h_{C}\right)
$$

in accordance with the draft New zealand codel7 requirements. This would have allowed approximately one third of the joint shear reinforcement of Unit 1 to be used, unless other criteria had dictated the use of more joint reinforcement.

To create a somewhat more critical situation, the flexural strength of the beam of Unit 2 was increased by $43 \%$ with the addition of 2-D24 bars, as shown in Fig. 4 . By taking into account the beneficial influence of the axial compression, in accordance with Eq. (2), this beam load would have required $41 \%$ of the horizontal joint shear force to be resisted by reinforcement, to satisfy code requirements.

After the completion of the test of Unit 1 , it became obvious that no joint distress was likely to be encountered with Unit 2 if tested as planned. In order to produce more critical conditions for the joint core, the axial load for Unit 2 was drastically reduced to $N=0.15 \mathrm{f}_{C}^{\prime} \mathrm{A}_{\mathrm{g}}$. 
With this reduced load, the horizontal joint shear reinforcement in the specimen represented only 618 of the amount required by the code17. This deficiency was considered to be sufficiently large to lead to early joint distress.

UNIT 3 was constructed after the behaviour of Unit 1 was observed. It was decided that Unit 3 be made exactly the same as Unit 1, except that only half of the horizontal joint shear reinforcement would be provided. Again with this theoretical deficiency of joint shear strength, distress of the joint at some stage of the loading sequence was expected.

\section{OBSERVED BEHAVIOUR}

\subsection{UNIT 1}

The overall performance of the unit is best described by its load-displacement response, shown in Fig. 6. The deflection is that of the tip of the beam at the load point. The theoretical applied beam load $\mathrm{P}_{i}$, corresponding with the development of the ideal flexural strength of the beam, is different for upward (positive) and downward (negative) loading because allowance has been made for the weight of the beam. Fig. 6(a) shows the elastic response during the first two cycles up to $75 \%$ of the yield load. In Fig. 6(b) the full inelastic hysteretic response may be seen. Excellent energy dissipation was demonstrated even up to a displacement ductility of $\mu=8$. The deflection at this stage would correspond with an interstorey drift of approximately 1/30 of storey height. The test was terminated in the loth cycle when a displacement ductility of $\mu=20$ was imposed, while the load sustained was $43 \%$ in excess of the ideal beam capacity. The loss of stiffness towards the end of the test was partly due to significant shear sliding in the plastic hinge zone of the beam.

Only minor cracking occurred in the joint region, as may be seen in Fig. 9. The average observed stirrup tensile strains within the joint barely exceeded 50 \% of the yield strain. Only at one location did the strain in one stirrup exceed $75 \%$ of that at yield, in the loth cycle of loading.

The test thus indicated that the horizontal joint shear reinforcement, designed to carry the full joint design shear force, could have been drastically reduced.

\subsection{UNIT 3}

As Table I shows this unit was identical to Unit 1 except for somewhat larger concrete strength and the horizontal joint shear reinforcement which was provided to resist $55 \%$ of the design horizontal joint shear force. In spite of this low shear steel content, excellent performance was observed, as seen in Fig. 7. Because of the slightly larger stiffness, as indicated by the elastic response in Fig.7, the beam deflection at a given displacement factor was some $12 \%$ less than that observed in Unit 1. The test was terminated when $137 \%$ of the theoretical strength of beam was developed at a displacement ductility of $\mu=21$.
Joint stirrup strains, measured at the centre of all four legs in three sets of stirrups within the joint, indicated that yielding was being approached in the 8 th cycle at a ductility of $\mu=6$. In cycle 12 at $\mu=10$, all stirrups yielded but only at the centre region of the joint core. Stirrup ties closer to the beam bars were stressed highly but they did not yield. Thus an uncontrolled opening of the potential diagonal crack across the joint, as seen in Fig. 9, did not develop. The test indicated that the joint shear reinforcement was well utilised and that, in spite of the small quantity used, it was adequate to ensure that the response of the unit was fully controlled by the plastic hinge region of the beam.

\subsection{UNIT 2}

Approximately $44 \%$ larger load was required in this unit to cause yielding of the flexural reinforcement in the beam. Because the column reinforcement used was the same as in the other units, during the final stages of loading the theoretical reserve strength of the column with respect to the load input from the beam was marginal. Indeed in the loth cycle of loading, when subjected to tension, all instrumented column corner bars yielded at levels of the beam horizontal reinforcement.

With the horizontal joint shear reinforcement being provided for only $61 \%$ of the designvalue, excellent response was obtained also in this unit in 10 cycles of loading up to $\mu=8$, as may be seen in Fig. 8. This displacement corresponds with a storey drift of $1 / 27$ of the storey height. In spite of a significant reduction in stiffness during negative loading in the loth cycle, no visible distress in the joint region was observed. However, there were many more and larger cracks in the joint region than in the other units.

In an attempt to create more critical conditions for the joint, the axial load on the column was reduced in the llth load cycle by $50 \%$ to $0.075 \mathrm{f}_{\mathrm{C}}^{\prime} \mathrm{A}_{\mathrm{g}}$. The dramatic reduction of stiffness and strength and consequent energy dissipation in the second half of the lith cycle and in the l2th load cycle, may be seen in Fig. 8. The displacement was subsequently increased to the limit of the loading facility, when a ductility $\mu=17$ was attained with the development of 107\% of the theoretical beam strength. In contrast to the other units the distress of the joint became then quite visible, as seen in Fig. $10(a)$.

Yielding of the joint stirrups was not recorded while displacements corresponding with $\mu=4$ were imposed. However from cycle 7 onwards, yielding had progressively spread in all four legs of the joint ties, particularly in the two central sets. In the loth cycle strain gauges on several stirrup legs indicated 6 times yield strain. Beam end-deflection due to only shear distortions within the joint, when a load corresponding with $\mu=8$ was imposed on Unit 2, was approximately 3 times as much as in the other two units. 


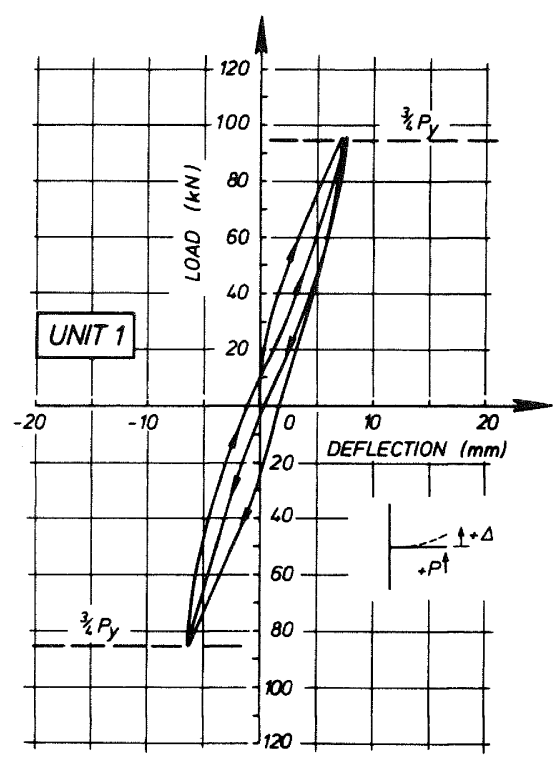

(a)

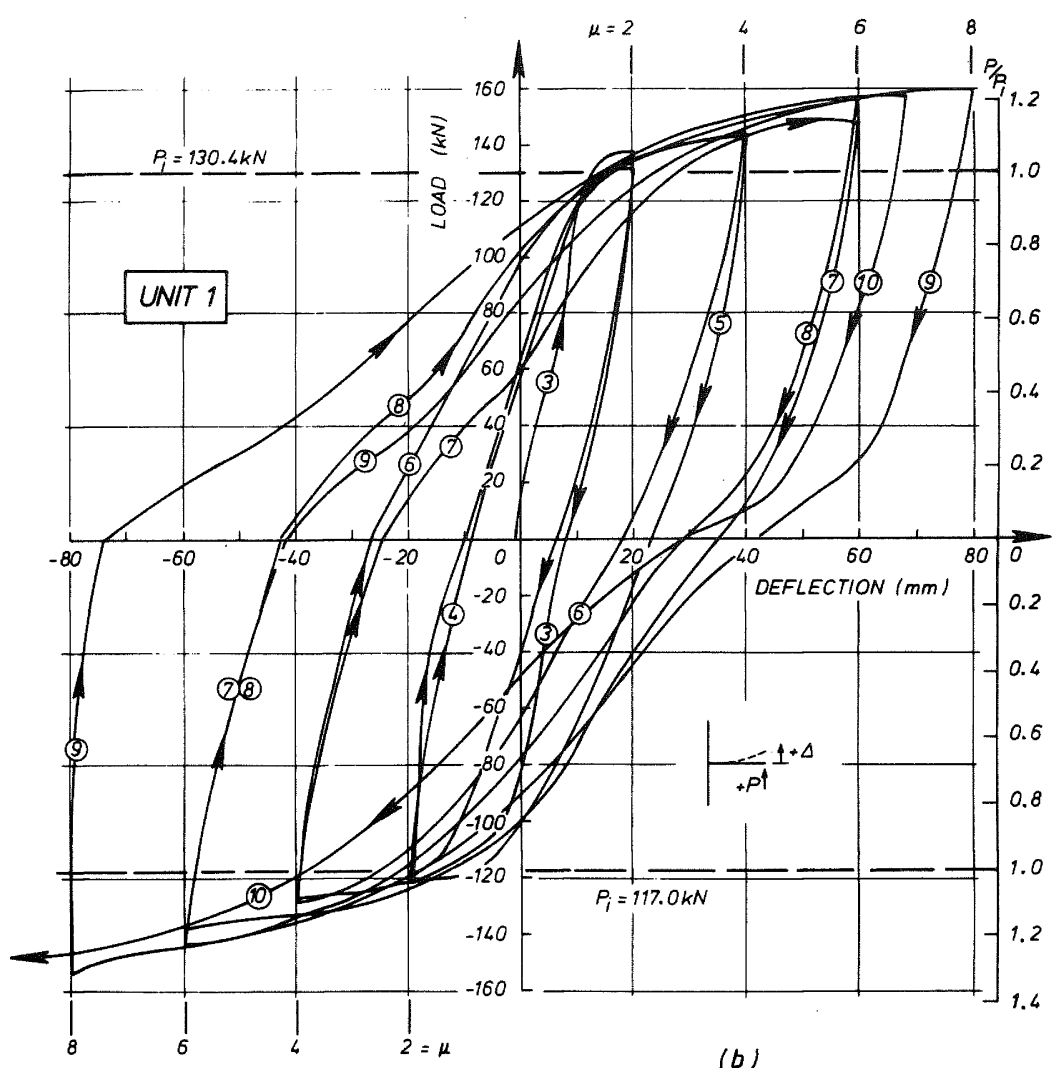

(b)

FIGURE 6 - LOAD-DISPLACEMENT RESPONSE OF UNIT 1
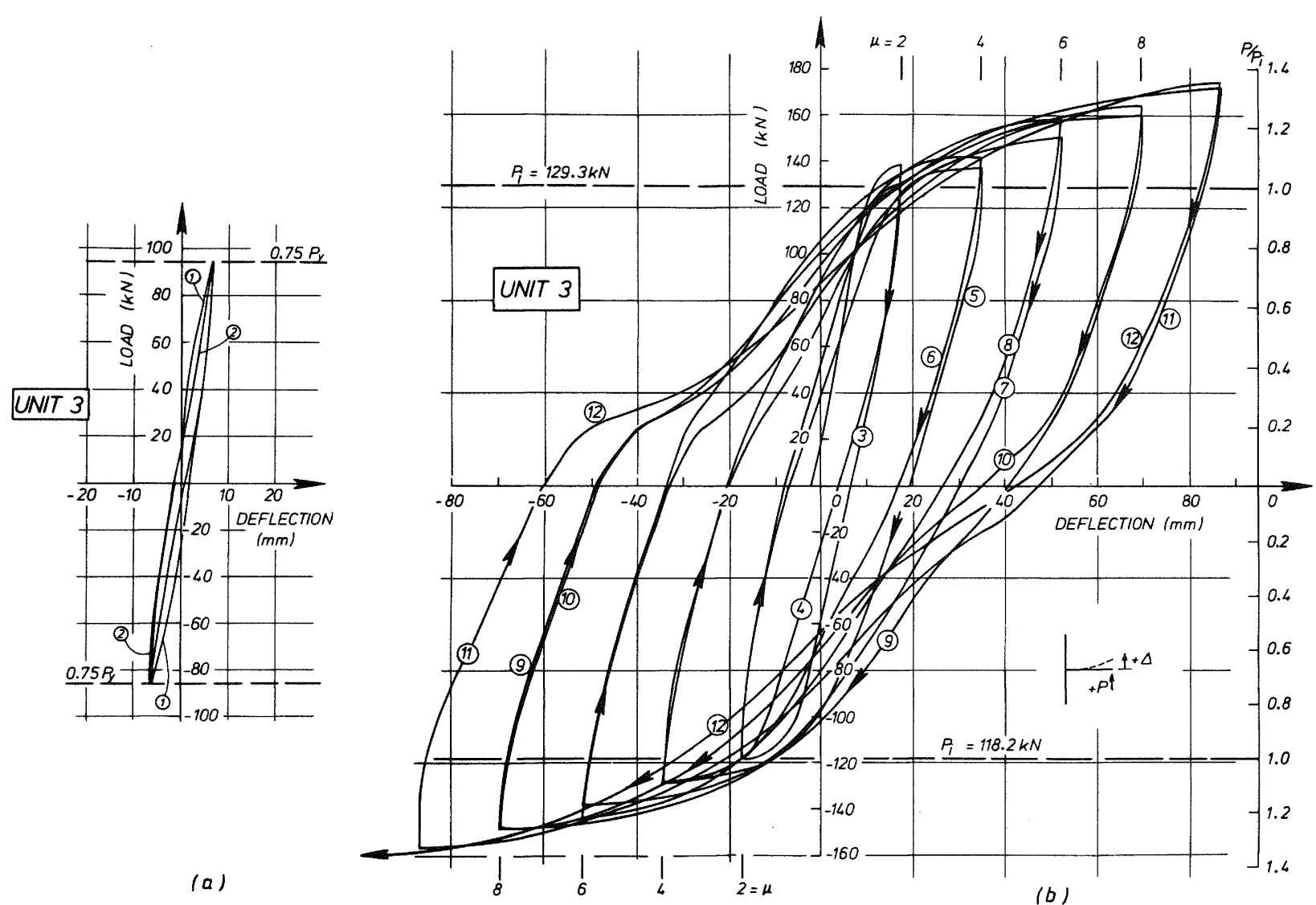

FIGURE 7 - LOAD-DISPLACEMENT RESPONSE OF UNIT 3 


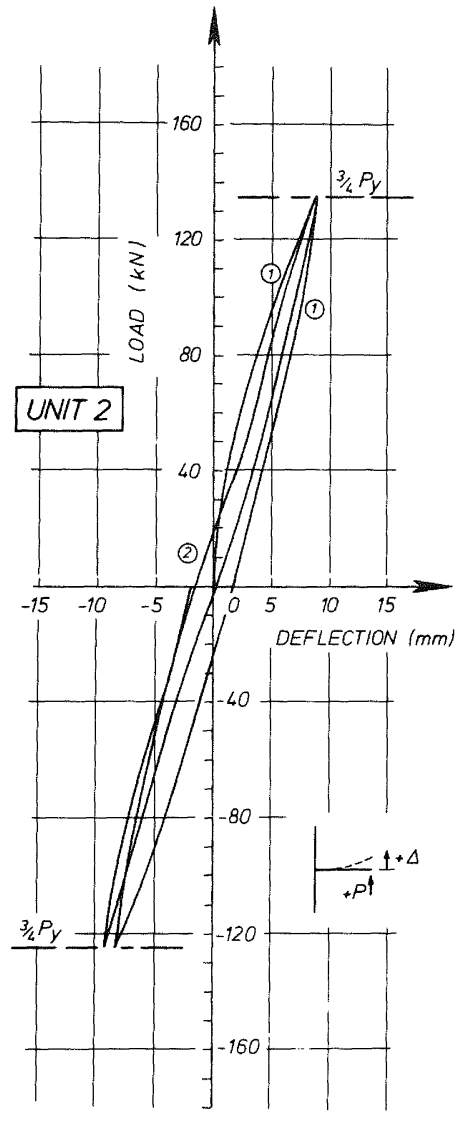

(a)

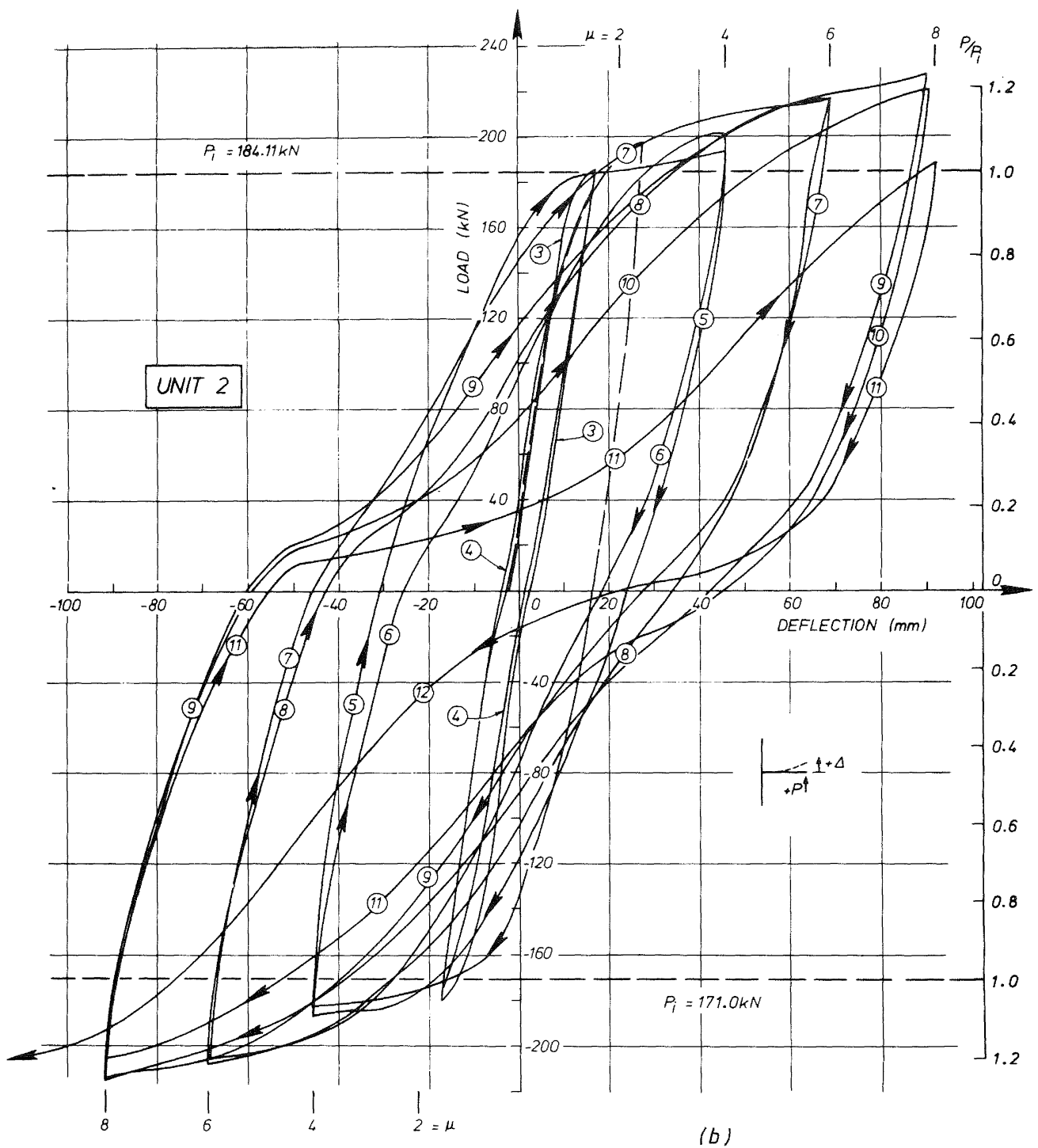

FIGURE 8 - LOAD-DISPLACEMENT RESPONSE OF UNIT 2

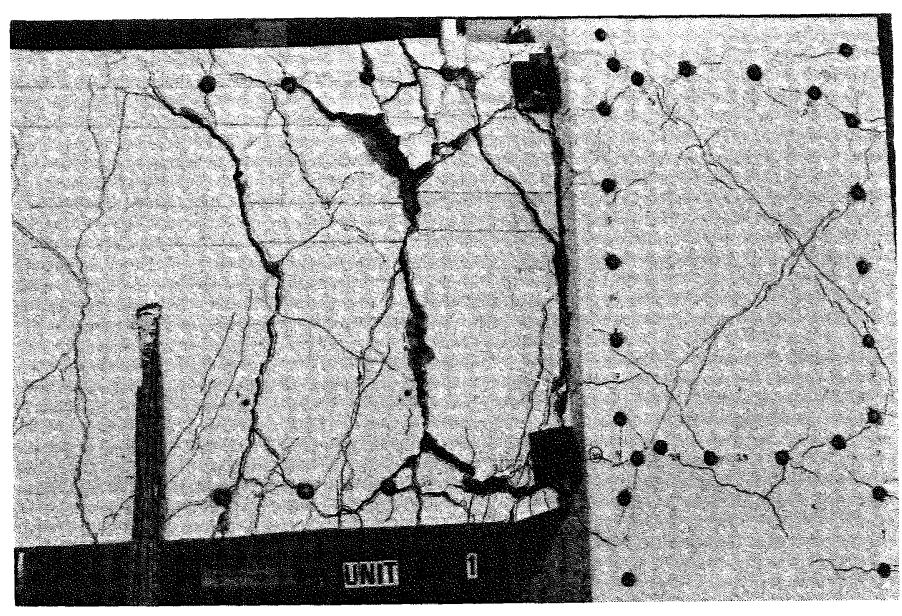

UNIT 1

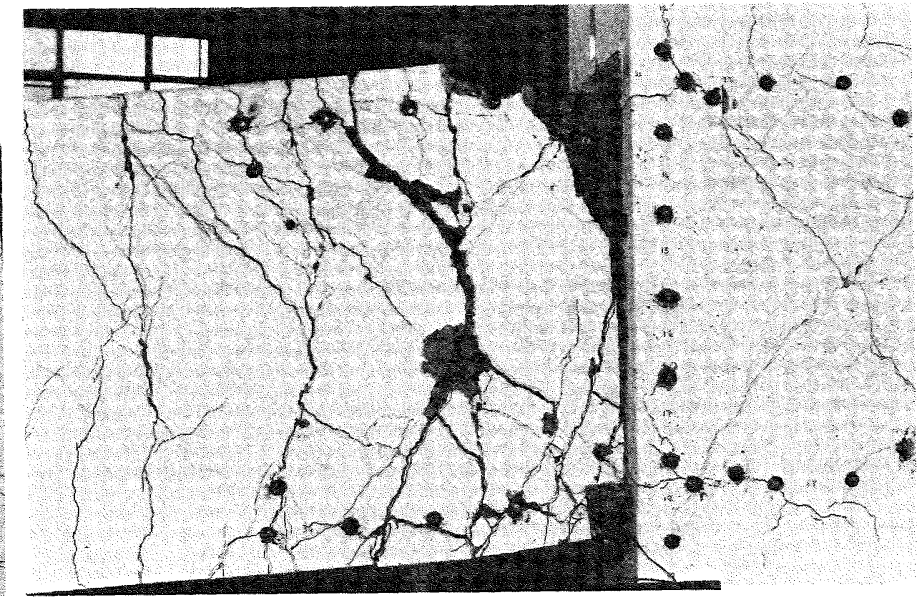

UNIT 3 
In spite of an eventual joint shear failure, the performance of this unit, in which horizontal joint shear reinforcement was provided for only $48 \%$ of the design shear force and $61 \%$ of the shear specified by current codel7 requirements, must be considered as very satisfactory.

\subsection{The Anchorage of Beam Bars}

The response of the flexural bars in the four corners of the beam section was monitored by mechanical strain gauges. Fig. 11 shows the spread of yielding along the outer top bars in the beam of Unit 1 in both directions from the inner face of the column, with progressive increase of imposed ductility $\mu$. Yield penetration into the joint is of particular interest. It is seen in Fig. 11 that by cycle $6(\mu=4)$ yielding has occurred close to the beginning of the bend in the beam bar. Change of stresses and hence bond stresses over the approximately $300 \mathrm{~mm}$ straight length of the beam bar from the inner face of the column towards the hook, were small, being due to strain hardening only. Thus a significant portion of the bond transfer over this length was lost and the beam bar relied for development of its strength mainly on the $90^{\circ}$ hook. In Unit I only, the straight part of the beam bar following the bend was inadvertently made $120 \mathrm{~mm}$ shorter than the specifiedl7 distance. In spite of this no distress in anchorage of the beam bars was observed at any stage.

Fig. 11 is typical of the strain pattern observed also in the other units for both top and bottom beam bars. In Unit 2 , however, tensile strains up to 6 times that at yield were measured in the loth load cycle over the last gauge length adjacent to the bend.

\subsection{Column Behaviour}

As all columns were designed to have flexural strength in excess of the maximum demand, as would be the case in ductile earthquake resisting frames in New Zealand17, no distress of any kind was expected. None were observed.

The integrity of the joints seemed to have ensured the satisfactory anchorage of the column bars passing through. In previous tests 4,6 , the cover concrete over the back of the column, opposite to the beam, was observed to be heavily cracked and in several cases it separated from the core or it had fallen off completely. Typical cases observed in early tests 5,6 are shown in Fig. $10(\mathrm{~b})$ and (c). Separation of back cover concrete could be detected by the hollow sound of tapping 5,6 . This has often lead to loss of bond along column bars. No such distress was observed in these tests except in Unit 2 when a load corresponding with $\mu=8$ was applied.

The observed strain distributions along the outer corner bars in the column of Unit 2 , in this respect the most critical ones, are presented in Fig. 13. A stable response with an approximately constant strain gradient throughout the test is evident. The average bond stresses around the D20 column barswere of the order of $4.5 \mathrm{MPa}$ when loading with $\mu=6$ to 8 was imposed on the unit. This is approximately twice the value of bond stress implied by the codel7 for the development of the bar strength by straight embedment in concrete.

\subsection{Features of Beam Behaviour}

The beams of all three units showed excellent behaviour. With the progressive severity of the loading, resulting in ever increasing inelastic tensile strains in the flexural bars, shear sliding along several full depth interconnected cracks became more significant. Fig. 12 shows such displacements in Unit 1. The magnitudes of various components of beam end deflections in Unit 1 are shown in Fig. 14 for increasing imposed ductilities. The elastic deflections were computed for both the beam and the column. Deflections due to slip of beam bars within the joint could not be quantified from measurements. It is seen that deflections due to shear distortions within the joint are not significant. However, this was not the case in Unit 2 .

Shear displacements in the plastic hinge regions of beams became significant when loads corresponding with $\mu=6$ or larger were imposed. This could have been controlled by diagonal reinforcement. However, the small loss of energy dissipation due to shear sliding, as evidenced by the hysteresis loops of Figs. 6,7 and 8 does not warrant such complication in detailing. The maximum shear stress, attained in the beam of Unit 2, was of the order of $0.24 \sqrt{\mathrm{fl}}$ $\mathrm{MPa}$. The New Zealand draft concrete codel7 requires the provision of some diagonal shear reinforcement when in similarly loaded beams shear stresses are in excess of $0.3 \sqrt{f_{c}^{1}}$.

It was found that the predicted flexural overstrength of the beams, based on $125 \%$ of the nominal yield strength of the steel, agreed satisfactorily with the observed values when the loading corresponded with $\mu= \pm 6$.

\subsection{Joint Performance}

The highlight of this study was the performance of the joints in Units 2 and 3. The horizontal shear reinforcement in both of these was approximately one half of that currently recommended in New Zealandl7. This amount was sufficient also to ensure the very satisfactory anchorage in the joint of both the beam and column reinforcement. From a comparison with tests performed earlier $4,5,6,7$ it appears that the use of intermediate column bars as vertical joint shear reinforcement, which were completely absent in earlier specimens, was responsible for this satisfactory behaviour. It is to be noted, however, that while the horizontal joint shear reinforcement was drastically reduced in Units 2 and 3 by comparison to that in Unit 1 , the vertical shear reinforcement (i.e. intermediate column bars) was the same in all units. A corresponding reduction in vertical joint shear reinforcement might have resulted in less satisfactory performance. 


\section{AN ALTERNATIVE JOINT MODEL}

In a search for an acceptable explanation for the surprisingly good performance of these beam-column joint specimens, use was made of a possible stress path, recently suggested by Fenwick and Nguyen 21 .

As explained earlier (Fig. 2(a)) the traditional assumption postulates a principal diagonal thrust within the joint along a corner to corner diagonal. However, it may be possible that the inclination of the strut, bearing against the bend of the beam bars, is steeper 21 , as shown in Fig. 15 (a). This is only possible if column ties, placed outside of, but, close to the joint core, can supply the necessary additional horizontal thrust (Fig. 15(a)). If this does happen, the question arises : How are these tie forces being balanced at the outer face of the column?

At this stage of the response the compression force from the adjacent beam can be transferred by the beam compression reinforcement only. This necessitates bond forces which could then develop inclined compression stresses as shown in Fig. 15 (b) Thus it is possible, as Fenwick and Nguyen $2 i$ suggested, that inclined compression forces engage column ties below the joint so that a steeper but more efficient strut, as shown in Fig. 15 (c) can develop.

In these test units at least two or perhaps three sets of column joint ties, placed immediately below or above the joint as seen in Fig. 4, could have participated in the actions of the model shown in Fig. 15 (c). For Units 2 and 3 such ties could have increased the assumed contribution of the horizontal joint shear reinforcement by 75 to $100 \%$. This may well be the reason for the excellent performance of the test units.

\section{SUMMARY AND CONCLUSIONS}

The behaviour of three exterior beamcolumn units, representative of a medium height multistorey frame, were reported. The purpose of the test was to identify the performance of the joint region when joint shear reinforcement in accordance with proposed New Zealand codel7 provisions was provided. These design provisions, however, were based on the study of more severely loaded interiorbeam column joints.

It was found that units with approximately $50 \%$ of the recommended horizontal joint shear reinforcement performed very satisfactorily. It is believed that the reasons for this are:

Intermediate column bars passing through the joint, but completely absent from similar test units tested several years ago, were provided. For practical reasons these were well in excess of the amount required by current design recommendations 17 . A deliberate reduction of vertical joint shear reinforcement to $50 \%$ of that currently recommended 17 might have had adversely affected joint performance.

(ii) A diagonal compression strut mechanism, at an angle considerably steeper than the principal diagonal of the joint core, may well utilize the contribution of joint ties, placed in the column close to but outside the joint core. Units, similar to those of this series but specially instrumented, in which column ties in the vicinity of the joint core are drastically reduced or eliminated, without causing a shear failure in the column, would need to be tested to confirm the working or such a mechanism.

The experimental study reported here indicates that the horizontal joint shear reinforcement in commonly used exterior beam-column units of multistorey ductile frames may well be reduced considerably. Further tests are desirable to verify the detailing requirements for the columns, in terms of transverse stirrup ties outside the joint and the use of intermediate column bars, that are necessary to permit this reduction of horizontal joint shear reinforcement to be formulated. It may well be that the necessary stirrup-tie reinforcement within exterior beam-column joints will be governed by other requirements, such as the confinement of the column.

\section{ACKNOWLEDGMENTS}

The experimental work reported here was carried out by A. Scarpas in partial fulfillment of the requirements for the degree of Master of Engineering, at the Department of Civil Engineering of the University of Canterbury. The invaluable assistance of $\mathrm{Mr}$. N. Hickey and $\mathrm{Mr}$. P. Mitchell, who were responsible for building the test specimens and assisting with the testing, of $\mathrm{Mr}$. L. Gardner with photography and of Mrs. V. Grey with drafting services is gratefully acknowledged.

The undertaking of the project would not have been possible without the financial assistance provided by the New Zealand Ministry of Works and Development.

\section{REFERENCES}

1. Hanson, N.W. and Conner, H.W., "Seismic Resistance of Reinforced Concrete Beam-Column Joints", Proceedings of the Structural Division, American Society of Civil Engineers, Vol. 93, No. ST5, October 1967, pp. 533-560.

2. Hanson, N.W., "Seismic Resistance of Concrete Frames with Grade 60 Reinforcement", Proceedings of the Structural Division, American Society of Civil Engineers, Vol. 97, No. ST6, June 1971, pp. 1685-1700.

3. Hanson, N.W. and Conner, H.W. "Tests of Reinforced Concrete Beam-Column Joints Under Simulated Seismic Loading", Portland Cement Association Research and Development Bulletin, RDO12.01D, 1972 .

4. Megget, L.M. and Park, R., "Reinforced Concrete Exterior Beam-Column Joints Under Seismic Loading", New Zealand Engineering, Vol. 26, No. 11 , pp. 341-353. 


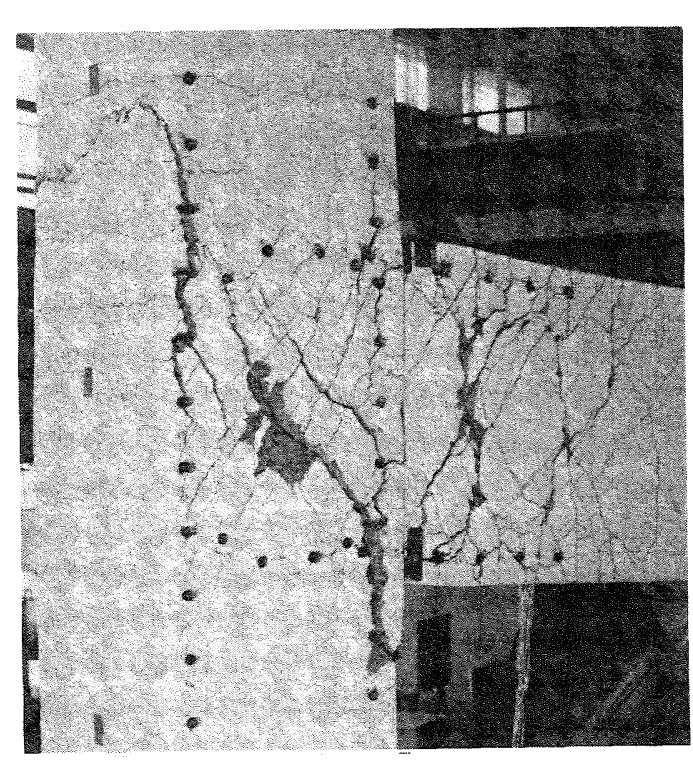

(a) UNIT 2

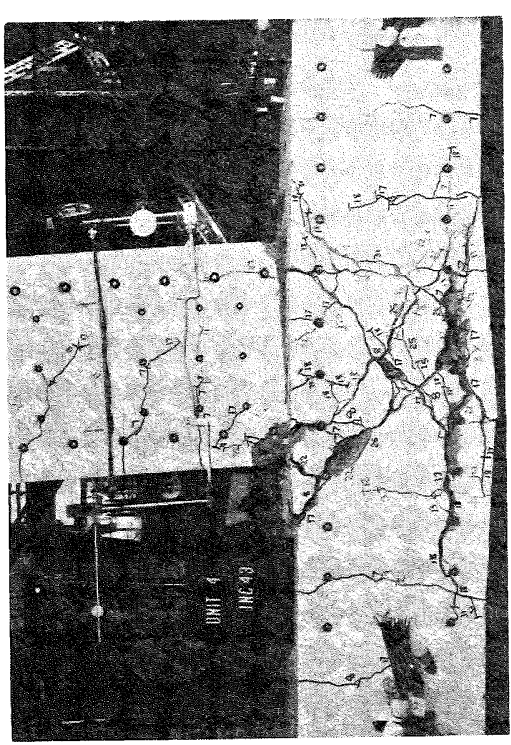

(b) SMITH (1972)

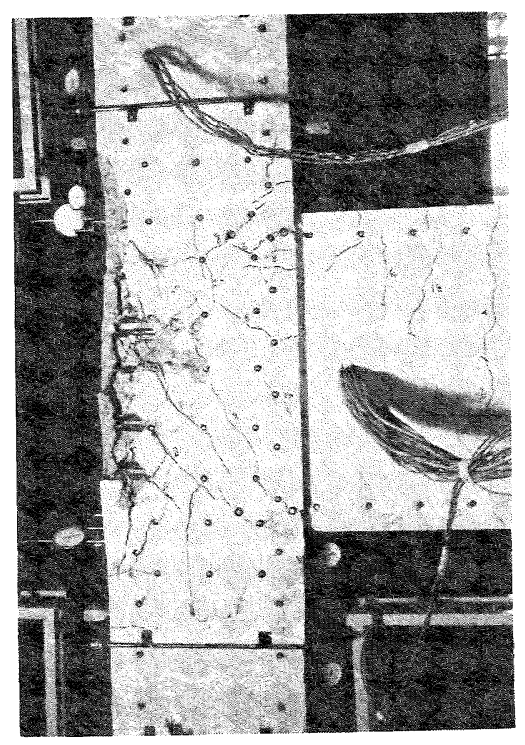

(c) RENTON (1972)

FIGURE 10 - THE FAILURE OF EXTERIOR BEAM-COLUMN JOINTS
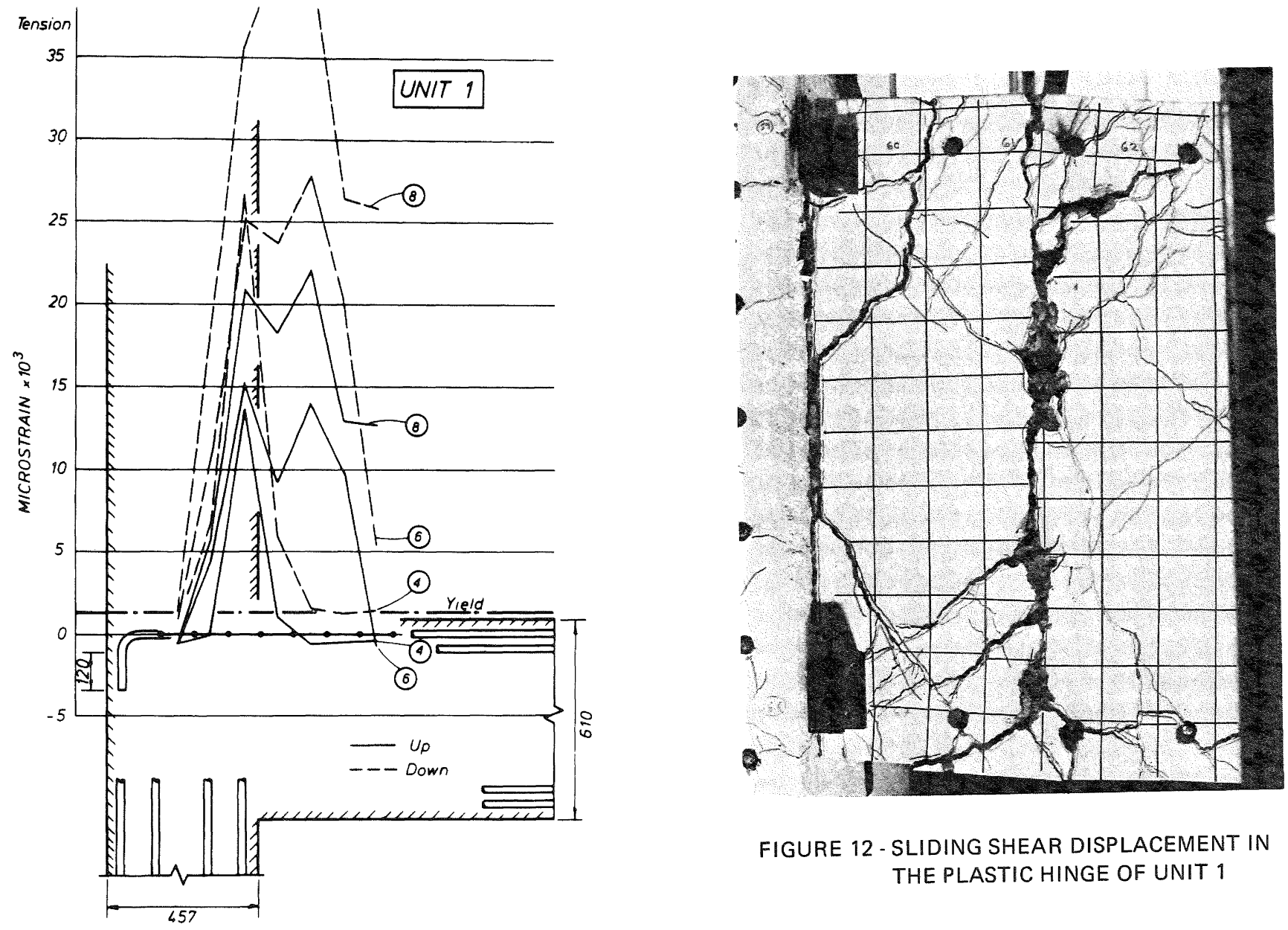

FIGURE 12 - SLIDING SHEAR DISPLACEMENT IN THE PLASTIC HINGE OF UNIT 1

FIGURE 11 - SPREAD OF YIELDING ALONG THE TOP BEAM BARS OF UNIT 1 

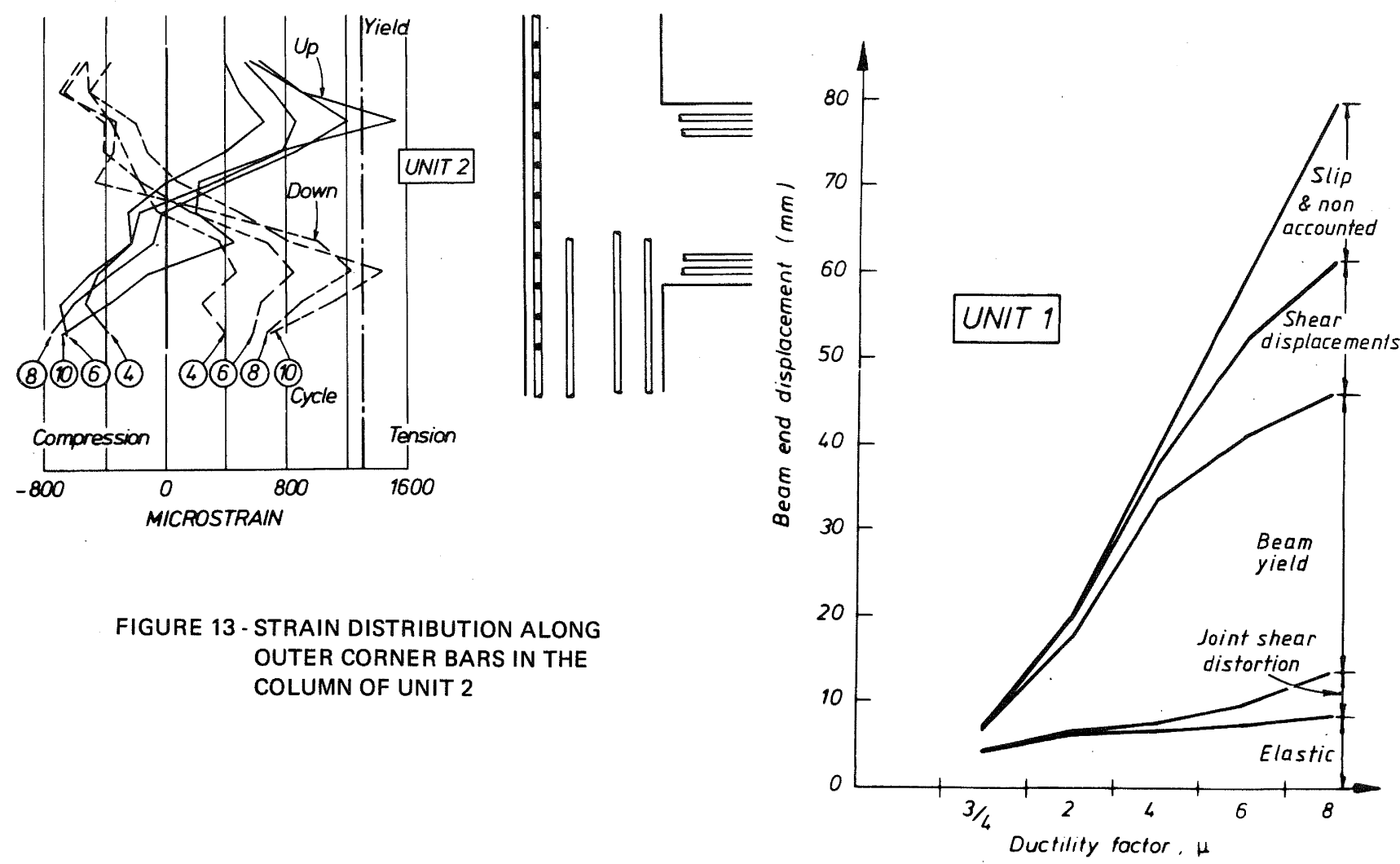

FIGURE 14 - DEFLECTION COMPONENTS OF THE BEAM OF UNIT 1
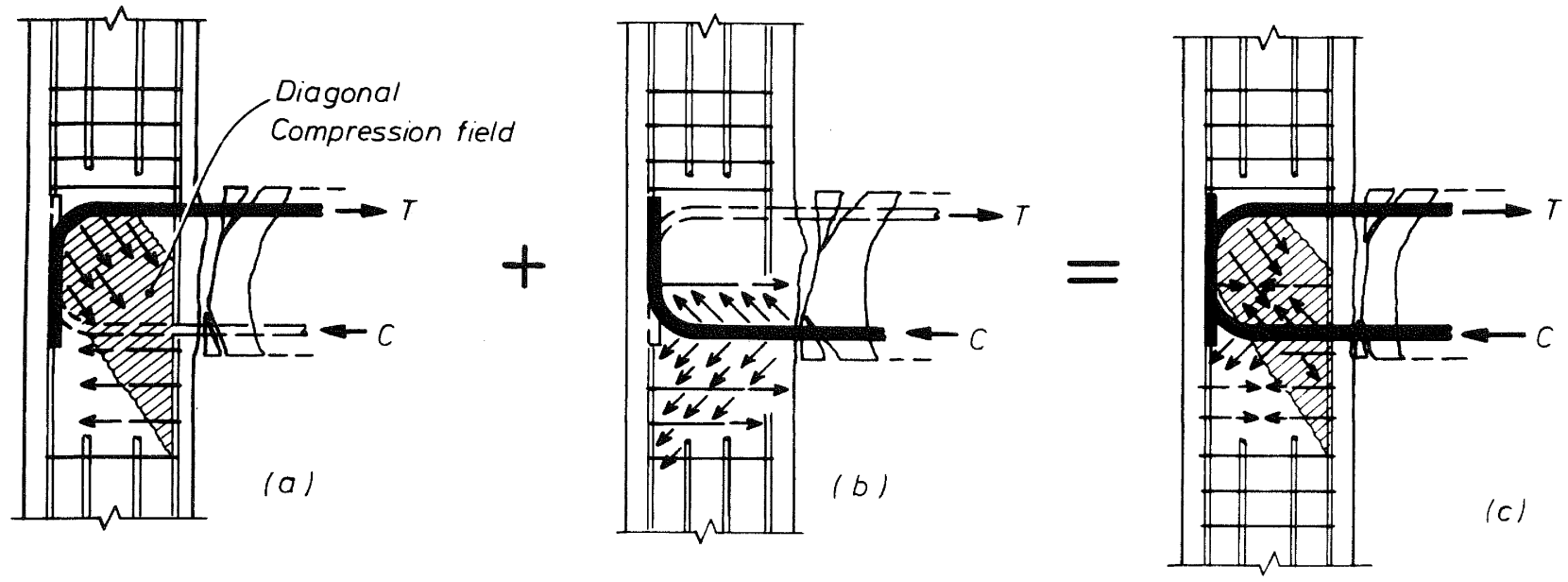
5. Smith, B.J., "Exterior Reinforced Concrete Joints with Low Axial Load Under Seismic Loading", Master of Engineering Report, University of Canterbury, February 1972, 91 p.

6. Renton, G., "The Behaviour of Reinforced Concrete Beam-Column Joints Under Cyclic Loading", Master of Engineering Report, University of Canterbury, February 1972, 162 p.

7. Patton, R.N., "Behaviour Under Seismic Loading of Reinforced Concrete BeamColumn Joints with Anchor Blocks", Master of Engineering Report, University of Canterbury, February 1972, $94 \mathrm{p}$.

8. Megget, L.M., "Cyclic Behaviour of Exterior Reinforced Concrete BeamColumn Joints", Bulletin of the New Zealand National Society for Earthquake Engineering, Vol. 7, No. 1 , March 1974, pp. 27-47.

9. SEAOC, "Recommended Lateral Force Requirements and Commentary", Seismology Committee, Structural Engineers' Association of California, San Francisco, $1973,146 \mathrm{p}$.

10. Park, R. and Paulay, T., "Reinforced Concrete Structures", John Wiley and Sons, New York, 1975, 769 p.

11. Paulay, T., Park, R. and Priestley, M.J.N., "Reinforced Concrete BeamColumn Joints Under Seismic Actions", Journal of the American Concrete Institute, Proceedings, Vol. 75, No. 11, November 1978, pp. 585-593.

12. Blakeley, R.W.G., "Seismic Design of Ductile Moment Resisting Reinforced Concrete Frames", Section J, Design of Beam-Column Joints, Bulletin of the New Zealand National Society for Earthquake Engineering, Vol. 10, No. 4, December 1977, pp. 226-237.

13. Blakeley, R.W.G., Megget, L.M. and Priestley, M.J.N., "Seismic Performance of Two Full Size Reinforced Concrete Beam-Column Joint Units", Bulletin of the New Zealand National Society for Earthquake Engineering, Vol. 8, No. 1, March 1975, pp. 38-69.

14. Beckingsale, C.W., "Post-Elastic Behaviour of Reinforced Concrete BeamColumn Joints", Ph.D. Thesis, Department of Civil Engineering, University of Canterbury, April 1980, 359 p.

15. Keong, Yeoh Sik, "Prestressed Concrete Beam-Column Joints", Research Report No. 78/2. Department of Civil Engineering, University of Canterbury, 1978, $81 \mathrm{p}$.

16. Park, R. and Yeoh Sik Keong, "Tests on Structural Concrete Beam-Column Joints with Intermediate Column Bars", Bulletin of the New Zealand National Society for Earthquake Engineering, Vol. 12, No. 3, September 1979, pp. 2361-2376.
17.

DZ3101 2nd Draft New Zealand Standard, "Code of Practice for the Design of Concrete Structures", Standards Association of New Zealand, Wellington, 1980 .

18. Scarpas, A., "The Inelastic Behaviour of Earthquake Resistant Reinforced Concrete Exterior Beam-Column Joints", Research Report No. 81/2, Department of Civil Engineering, University of Canterbury, $1981,128 \mathrm{p}$.

19. Birss, G.R., "The Elastic Behaviour of Earthquake Resistant Reinforced Concrete Interior Beam-Column Joints", Research Report 78/13, Department of Civil Engineering, University of Canterbury, February 1978, 96 p.

20. Park, R. and Paulay, T., "Behaviour of Reinforced Concrete External BeamColumn Joints Under Cyclic Loading", Proceedings, Fifth World Conference on Earthquake Engineering, Paper 88, Vol. 1, Session 2D, Rome, June 1973, pp. 772-781.

21. Fenwick, R.C. and Nguyen, H.T., "Reinforced Concrete Beam-Column Joints for Seismic Loading", Report No. 220, Department of Civil Engineering, University of Auckland, 1981, $62 \mathrm{p}$. 